\title{
Evaluation of lipid profile among children and adolescents with type 1 diabetes mellitus in Bangladesh
}

\author{
M Parveen ${ }^{1 凶}$, MA Muttalib ${ }^{2}$, ST Huq ${ }^{3}$, N Nazneen ${ }^{4}$, MA Kabir ${ }^{5}$, MS Hossain ${ }^{6}$
}

\begin{abstract}
The study, a cross-sectional survey, was carried out at the Department of Biochemistry in Bangladesh Institute of Research and Rehabilitation in Diabetes, Endocrine and Metabolic Disorders (BIRDEM) General Hospital from July 2015 to June 2016. A total of 576 clinically diagnosed children and adolescents with type 1 diabetes mellitus (T1DM) aged 10-18 years attending in 'Changing Diabetes in Children' clinic, BIRDEM-2, Dhaka were selected according to appropriate inclusion and exclusion criteria. The study subjects underwent detailed medical history and examination. Fasting blood samples were drawn from the participants for biochemical assays such as fasting blood sugar (FBS), glycated haemoglobin (HbA1c), total cholesterol, low-density lipoprotein cholesterol, high-density lipoprotein cholesterol and triglycerides. Anthropometric data and blood pressures both systolic and diastolic were measured. Student unpaired t-test and Chi-square test were used to determine the association between different groups. Out of 576 T1DM patients, $45.0 \%$ (259) were male and $55.0 \%$ (317) were female. Of the 576 T1DM patients, $35.1 \%$ were without dyslipidemia (DLP) and $64.9 \%$ were with DLP. Study revealed that the patients with DLP were more likely to have higher values of $\mathrm{HbA} 1 \mathrm{c}(10.1 \pm 2.2 \%$ vs $9.4 \pm 1.9 \%, p<0.001)$ and $\mathrm{FBS}(13.0 \pm 4.4 \mathrm{mmol} / \mathrm{L}$ vs $10.2 \pm 2.9$ $\mathrm{mmol} / \mathrm{L}, p<0.001)$. A substantial proportion of children and adolescents with T1DM had DLP. We found an association between poor glycemic control and abnormal lipid profiles in those patients.
\end{abstract}

Key words: lipid profile, children, adolescents, type 1 diabetes mellitus, Bangladesh.

\section{Introduction}

Diabetes mellitus (DM) is a common endocrine disorder among children and adolescents in Bangladesh. ${ }^{1}$ The increasing incidence of childhood and adolescent DM is a global phenomenon. ${ }^{2}$ Type 1 DM (T1DM) accounts for majority of childhood and adolescent onset DM seen in population of developed world. ${ }^{3}$

Children diagnosed with T1DM have a high risk of early subclinical and clinical cardio- vascular disease (CVD). ${ }^{4}$ Risk of coronary heart disease is fourfold (in men) to eightfold (in women) in patients with T1DM. ${ }^{5}$ The American Heart Association categorizes children with T1DM in the highest tier for cardiovascular risk. ${ }^{4}$ CVD is the major complication responsible for more than $50 \%$ and up to $80 \%$ of deaths in people with DM. ${ }^{6}$

Dyslipidemia (DLP) is a preventable major risk factor for CVD. There are several studies that have evaluated DLP in patients with

\footnotetext{
1. M Parveen, Assistant Professor, Department of Biochemistry, Gazi Medical College, Khulna.

Email: mukta.parveen14@gmail.com

2. MA Muttalib, Professor, Department of Biochemistry, BIRDEM Academy, Dhaka

3. ST Huq, Assistant Professor, Department of Biochemistry, Prime Medical College, Rangpur

4. N Nazneen, Assistant Professor, Department of Community Medicine, Gazi Medical College, Khulna

5. MA Kabir, Assistant Professor, Department of Biochemistry, Diabetic Association Medical College, Faridpur

6. MS Hossain, Assistant Professor, Department of Biochemistry, Prime Medical College, Rangpur
} 
type 2 DM (T2DM), but DLP in patients with T1DM and especially young children with short duration of DM remains largely undiagnosed and untreated. ${ }^{7}$ The prevalence of hyperlipidemia in T1DM is approximately $20 \%-40 \%{ }^{8}$ The prevalence of DLP in the general population, including children, has recently increased. ${ }^{9}$ DLP in DM patients is likely to play an important role in the development of atherogenesis.

These lipid disorders include not only quantitative that is increased triglyceride levels related to elevated very low-density lipoproteins (VLDL) and Low-density lipoproteins (LDL) but also qualitative abnormalities of lipoproteins (large VLDL, small LDL) which are potentially atherogenic. Both types are present in poorly controlled insulin dependent DM (IDDM), whereas only qualitative abnormalities are observed in well and moderately well-controlled IDDM. ${ }^{10}$

Many studies have shown that micro vascular changes and precursors of atherosclerosis are frequently observed in young patients early in the course of T1DM. ${ }^{11}$ In T1DM, hyperglycemia leads to modification of proteins by nonenzymatic glycation of proteins leading to formation of advanced glycation end products. This process leads to microangiopathy, which results in the well-known complications of retinopathy, nephropathy and neuropathy. Macroangiopathy also occurs and is characterized by cardiovascular, cerebrovascular and peripheral vascular diseases. Hyperglycemia causes an atherogenic pattern of DLP, vascular inflammation and oxidative stress and vascular endothelial dysfunction. ${ }^{12}$

The aim of this study was to evaluate the presence of DLP among children and adolescents with T1DM. The lipid profile in children and adolescents with T1DM is not well documented in Bangladesh. Early screening of lipid profile may help for early detection of DLP and prevention of further complications of children and adolescents with T1DM in relation to DLP.
Materials and Method

\section{Subjects}

The study was conducted on clinically diagnosed T1DM children and adolescents between 10-18 years of age from 'Changing Diabetes in Children' clinic, BIRDEM-2, Dhaka, Bangladesh from the period of July 2015 to June 2016. The study was cross sectional, observational, descriptive and analytic type. The participants were selected through convenience sampling method. A total of 576 T1DM children and adolescents that had been diagnosed with T1DM were selected.

Inclusion criteria included clinically diagnosed T1DM age between 10 and 18 years, both male and female and no medications other than insulin. T1DM was diagnosed based on the World Health Organization \& International Society for Pediatric and Adolescent Diabetes (ISPAD) criteria in children and adolescents. The study was reviewed and approved by Ethical Review Committee of Bangladesh Diabetic Samity (BADAS) and all participants provided informed written consent and/or assent.

\section{Data collection and analysis}

During the study visit, detailed medical history was recorded in a structured questionnaire for each study subject including data about current age, sex, duration of DM, age at onset. An examination was performed to measure systolic and diastolic blood pressures, height, weight and body mass index (BMI). Blood samples for fasting blood sugar (FBS), glycated haemoglobin ( $\mathrm{HbA1c})$, total cholesterol (TC), low-density lipoprotein cholesterol (LDLC), high-density lipoprotein cholesterol (HDLC) and triglycerides (TG) were obtained under condition of metabolic stability after at least 8 hours of fasting.

Cut off points for abnormal lipid levels (TC $\geq$ $200 \mathrm{mg} / \mathrm{dl}, \mathrm{LDLC} \geq 130 \mathrm{mg} / \mathrm{dl}, \mathrm{TG} \geq 150 \mathrm{mg} / \mathrm{dl}$ and HDLC $<40 \mathrm{mg} / \mathrm{dl}$ for male and $<50 \mathrm{mg} / \mathrm{dl}$ for female) were taken from the Third Report of the National Cholesterol Education program and the American diabetes Association. ${ }^{13,14}$ DLP was defined by the 
presence of one or more abnormal serum lipid concentrations. For the present cross-sectional analysis, clinical data, FBS, HbA1c, BMI and lipid profiles were investigated in children and adolescents with T1DM. We compared the lipid profiles of patients with DLP and those without DLP. Student unpaired t-test and Chi-square test were used to determine the association between different groups.

\section{Results}

Table 1 shows the clinical and laboratory variables of the T1DM patients with DLP and without DLP. The mean $\pm S D$ age was $15.0 \pm 2.8$ years. The mean $\pm S D$ age at onset of DM in the study group was $11.2 \pm 3.4$ years. The mean $\pm S D$ values for fasting lipid measures were as follows: TC, $183.2 \pm 46.6$ $\mathrm{mg} / \mathrm{dl}$; LDLC, $98.3 \pm 29.7 \mathrm{mg} / \mathrm{dl}$; HDLC, $45.7 \pm 12.6 \mathrm{mg} / \mathrm{dl}$, and TG, $174.6 \pm 78.6 \mathrm{mg} / \mathrm{dl}$. The mean \pm SD level of FBS and $\mathrm{HbA} 1 \mathrm{c}$ of the patients were $12.0 \pm 4.2 \mathrm{mmol} / \mathrm{L}$ and $9.8 \pm 2.1 \%$, respectively. The $\mathrm{HbA} 1 \mathrm{c}$ of the patients with DLP was significantly higher than that of the patients without DLP (mean \pm SD, $10.1 \pm 2.2 \%$ vs $9.4 \pm 1.9 \% ; p<$ $0.001)$. Within the study group, comparison of the fasting serum lipid profile (mean $\pm S D$ ) between those with DLP and those without DLP revealed significantly higher values of TC, LDLC and TG, and significantly lower values of HDLC in the former (Table 1). There was no significant difference in age, age at the time of diagnosis of DM between the groups of T1DM patients with DLP and without DLP.
Fig. 1 shows the prevalence of DLP for patients with T1DM. Among the total 576 participants, $374(64.9 \%)$ were classified as having DLP due to the following lipid abnormality: TC $\geq 200 \mathrm{mg} / \mathrm{dl}$ in 195 (33.9\%), LDLC $\geq 130 \mathrm{mg} / \mathrm{dl}$ in $104(18.1 \%), \mathrm{TG} \geq 150 \mathrm{mg} / \mathrm{dl}$ in $313(54.3 \%)$ and low HDLC (<40 mg/dl in male, $<50 \mathrm{mg} / \mathrm{dl}$ in female) in $214(37.2 \%)$ subjects. No abnormality was detected in 202 subjects (35.1\%). The most common abnormality was high TG either alone or in combination with other lipid parameters.

Fig. 2 shows the distribution of study population according to gender. Among 576 participants, female gender constitutes $317(55.0 \%)$ of the study group while males constitute 259 $(45.0 \%)$. The female patients were significantly higher than male patients having DLP, $218(68.8 \%)$ vs $156(60.2 \%), p<0.05$.

Table 2 shows the association between the level of glycemic control and abnormal lipid profiles in study subjects. To evaluate the association between lipid values and glycemic control, we categorized patients into two groups. Participants with $\mathrm{HbA} 1 \mathrm{c}<9 \%$ as good to fair glycemic control and participants with $\mathrm{HbA} 1 \mathrm{c} \geq 9 \%$ as poor glycemic control. Participants with good to fair glycemic control $(\mathrm{HbA} 1 \mathrm{c}<9 \%)$ and abnormal cholesterol level (TC $\geq 200 \mathrm{mg} / \mathrm{dl}$ ) were $50(23.7 \%)$ compared to $145(39.7 \%)$ with poor glycemic control $(\mathrm{HbA} 1 \mathrm{c} \geq 9 \%)$ and abnormal lipids. The association was statistically significant $(p<$ $0.001)$. The patients, $31(14.7 \%)$, with elevated LDLC had good to fair glycemic control in comparison to $73(20.0 \%)$ with poor control. The association was not signifi-

Table 1. Clinical and laboratory variables compared between the groups of T1DM patients with DLP and without DLP, $n=576$

\begin{tabular}{|c|c|c|c|c|}
\hline Variables & $\begin{array}{r}\text { All patients } \\
(n=576) \\
\text { Mean } \pm S D\end{array}$ & $\begin{array}{r}\text { With DLP } \\
(n=374) \\
\text { Mean } \pm S D\end{array}$ & $\begin{array}{r}\text { Without DLP } \\
(n=202) \\
\text { Mean } \pm S D\end{array}$ & $p$ value \\
\hline $\begin{array}{l}\text { Age at the time of } \\
\text { diagnosis of DM, years }\end{array}$ & $11.2 \pm 3.4$ & $11.2 \pm 3.4$ & $11.4 \pm 3.4$ & $>0.05$ \\
\hline Age at visit, years & $15.0 \pm 2.8$ & $14.9 \pm 2.8$ & $15.2 \pm 2.8$ & $>0.05$ \\
\hline $\begin{array}{l}\text { FBS, mmol/L } \\
\text { HbA1c, \% } \\
\text { TC, mg/dl } \\
\text { LDLC, mg/dl } \\
\text { HDLC, mg/dl } \\
\text { TG, mg/dl }\end{array}$ & $\begin{array}{r}12.0 \pm 4.2 \\
9.8 \pm 2.1 \\
183.2 \pm 46.6 \\
98.3 \pm 29.7 \\
45.7 \pm 12.6 \\
174.6 \pm 78.6\end{array}$ & $\begin{array}{r}13.0 \pm 4.4 \\
10.1 \pm 2.2 \\
199.7 \pm 47.4 \\
106.7 \pm 31.8 \\
41.0 \pm 10.9 \\
211.6 \pm 73.1\end{array}$ & $\begin{array}{r}10.2 \pm 2.9 \\
9.4 \pm 1.9 \\
152.8 \pm 24.7 \\
82.6 \pm 16.3 \\
54.5 \pm 10.7 \\
106.0 \pm 21.4\end{array}$ & $\begin{array}{l}<0.001 \\
<0.001 \\
<0.001 \\
<0.001 \\
<0.001 \\
<0.001\end{array}$ \\
\hline
\end{tabular}




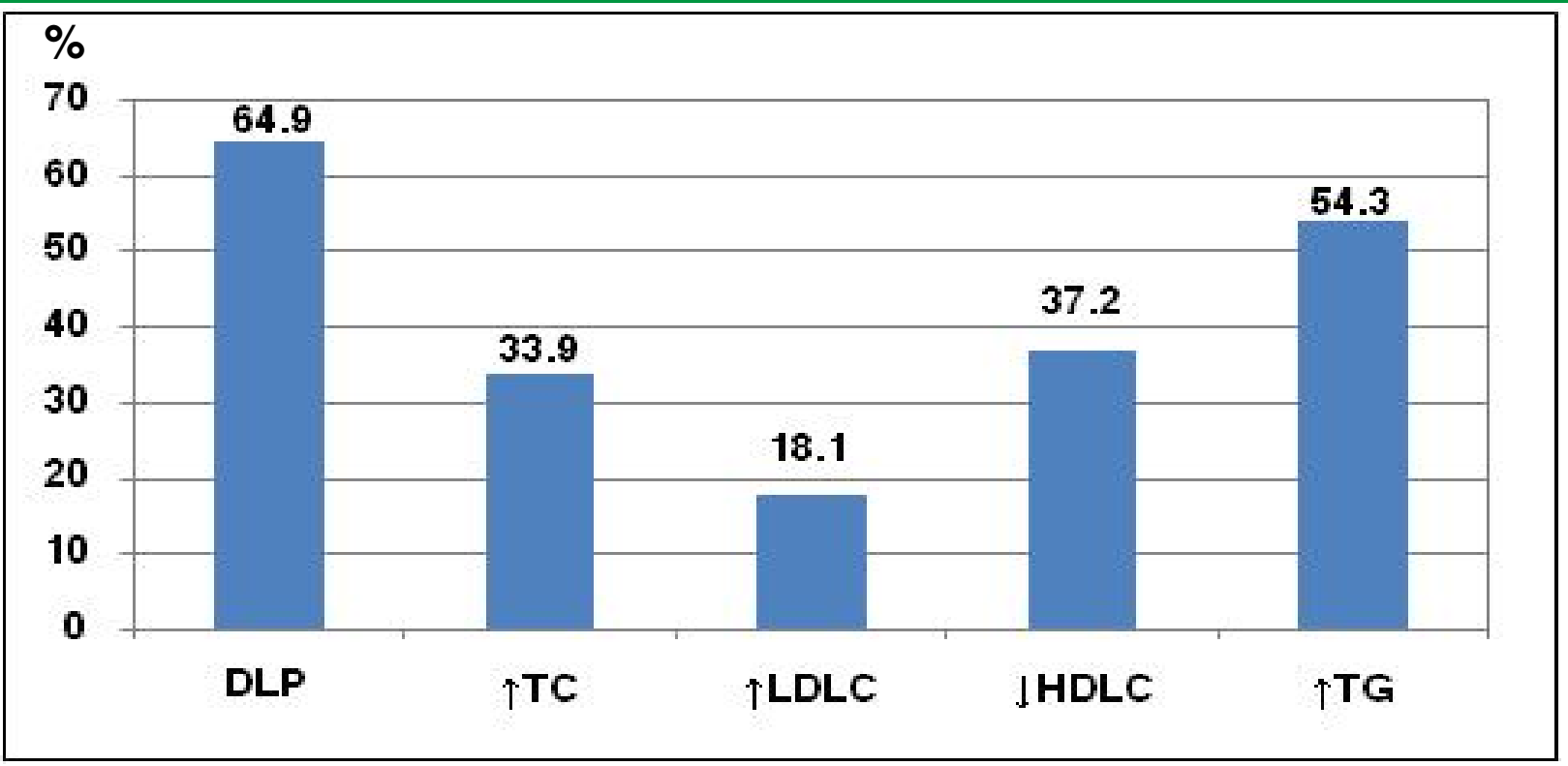

Fig. 1. Prevalence of DLP for patients with T1DM.

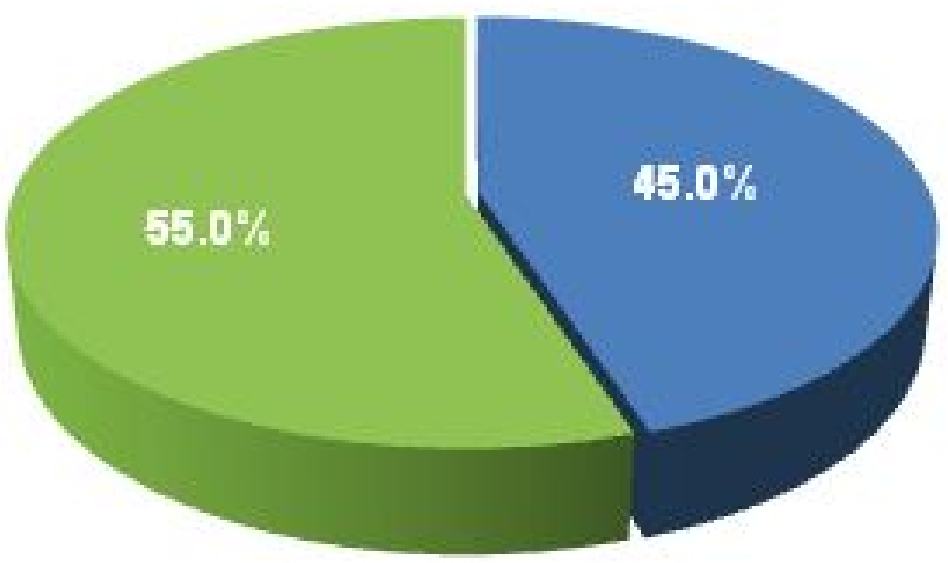

Male

Female

Fig. 2. Distribution of gender among study subjects.

Table 2. Association between the level of glycemic control and abnormal lipid profiles in study subjects, $n=576$

\begin{tabular}{|c|c|c|c|}
\hline \multirow{2}{*}{$\begin{array}{l}\text { Abnormal lipid profiles; number of } \\
\text { patients }\end{array}$} & HbA1c $<9 \%$ & HbA1c $\geq 9 \%$ & \multirow[t]{2}{*}{$p$ value } \\
\hline & Number (\%) & Number (\%) & \\
\hline TC $\geq 200 \mathrm{mg} / \mathrm{dl} ; 195$ patients & $50(23.7)$ & $145(39.7)$ & \multirow{2}{*}{$<0.001$} \\
\hline TC $<200 \mathrm{mg} / \mathrm{dl} ; 381$ patients & $161(76.3)$ & $220(60.3)$ & \\
\hline LDLC $\geq 130$ mg/dl; 104 patients & 31 (14.7) & 73 (20.0) & \multirow[b]{2}{*}{$>0.05$} \\
\hline LDLC $<130 \mathrm{mg} / \mathrm{dl} ; 472$ patients & $180(85.3)$ & $292(80.0)$ & \\
\hline TG $\geq 150$ mg/dl; 313 patients & 96 (45.5) & 217 (59.5) & \multirow{2}{*}{$<0.01$} \\
\hline TG $<150 \mathrm{mg} / \mathrm{dl} ; 263$ patients & $115(54.5)$ & $148(40.5)$ & \\
\hline $\begin{array}{l}\mathrm{HDLC}(<40 \mathrm{mg} / \mathrm{dl} \text { in male and } \\
<50 \mathrm{mg} / \mathrm{dl} \text { in female); } 214 \text { patients }\end{array}$ & $68(32.2)$ & $146(40.0)$ & \multirow[b]{2}{*}{$>0.05$} \\
\hline $\begin{array}{l}\mathrm{HDLC}(\geq 40 \mathrm{mg} / \mathrm{dl} \text { in male and } \\
\geq 50 \mathrm{mg} / \mathrm{dl} \text { in female); } 362 \text { patients }\end{array}$ & $143(67.8)$ & $219(60.0)$ & \\
\hline
\end{tabular}


cant $(p>0.05)$. The participants, $96(45.5 \%)$, with elevated TG ( $\geq 150 \mathrm{mg} / \mathrm{dl})$ had good to fair glycemic control in comparison to 217 (59.5\%) with poor control. The association was statistically significant $(p<0.01)$. Patients with low HDLC $(<40 \mathrm{mg} / \mathrm{dl}$ in male and $<50 \mathrm{mg} / \mathrm{dl}$ in female) with good to fair glycemic control were $68(32.2 \%)$ compared to $146(40.0 \%)$ with poor glycemic control. The association was not statistically insignificant $(p>0.05)$.

\section{Discussion}

To the best of our knowledge, there was a lack of data about serum lipid profiles in Bangladeshi children and adolescents with T1DM. In the present study, the overall prevalence of DLP among children and adolescents with T1DM was $64.9 \%$. This prevalence is higher than the $37.9 \%$ observed among Korean adolescents and young adults with T1DM and $39.2 \%$ among children with T1DM in United Kingdom. ${ }^{11,15}$ This finding has potential clinical significance, given the well-known relationship between DLP and cardiovascular events and the fact that lipid levels frequently track from childhood to adulthood. ${ }^{16}$ This result is similar to those reported in other studies. , $^{3,19}$ While the finding is different from a study where the prevalence of DLP in T1DM patients was $40.0 \% .^{20}$ In the current study, the most frequent type of DLP was high TG in $54.0 \%$ of the children and adolescents with T1DM, which was also found to be the most common type reported in some studies. ${ }^{21-24}$ High LDLC and low HDLC reported by Mona et $\mathrm{al}^{3}$ and high LDLC and hypercholesterolemia with and without hypertriglyceridemia by Rahma et $\mathrm{al}^{18}$ and Al-Naama et $\mathrm{al}^{25}$ were different to the present study.

Females outnumbered males in this study, which is similar to Ahmed ${ }^{19}$ and contradicts the study done by Pollak et $\mathrm{al}^{26}$ in which males outnumbered females. In this study, the female patients were significantly higher than male patients having DLP. This finding is in agreement with some other studies. ${ }^{3,9,27,28}$ Our finding is in contrast to the results reported by others who found that there was no relationship between the lipid abnormalities in children and adolescents with T1DM and the gender. ${ }^{17,22}$
$\mathrm{HbA} 1 \mathrm{c}$ is valuable and widely used to blood glucose determination for monitoring long term glycemic control. It is a measure of risk of complications of DM. It is a strong predictor of cardiovascular risk factors, cardiovascular events and strokes in DM patients. ${ }^{29}$ Maahs et al performed a retrospective analysis of subjects with T1DM by analyzing random lipid levels measured during clinical practice. ${ }^{30}$ Their study showed that $\mathrm{HbA} 1 \mathrm{c}$ positively associated with both TC and nonHDLC. Guy et al reported data from the SEARCH for Diabetes in Youth case-control study, in which T1DM subjects with a HbA1c target $<7.5 \%$ had lower prevalence of DLP, similar to healthy controls, while T1DM subjects with $\mathrm{HbA} 1 \mathrm{c} \geq 7.5 \%$ were more likely to have elevated TC and LDLC levels. ${ }^{31}$

In present study, the majority of the patients with DLP $(69.9 \%)$ had poor glycemic control (mean \pm SD HbA1c $10.1 \pm 2.2 \%$ ), while in the patients without DLP, most of them (56.4\%) had good to fair glycemic control (mean \pm SD HbA1c $9.4 \pm 1.9 \%$ ) with significant difference between the groups regarding $\operatorname{HbA1c}(p<$ $0.001)$. This result is in concordance with some researchers who found that poorer (inadequate) glycemic control is related to higher serum lipid levels. ${ }^{19,31,32}$ On the contrary, some researchers found that lipid disorders in children and adolescents with T1DM may be present regardless of their metabolic control. ${ }^{23,33}$ It was observed that abnormal TG and TC were higher in poor glycemic control $(\mathrm{HbA} 1 \mathrm{c} \geq 9 \%)$ compared to good to fair glycemic control (HbA1c <9\%) participants with significant association ( $p$ $<0.01$ and $p<0.001$, respectively); whereas, abnormal LDLC and HDLC were found in poor control group than good to fair control group but with no significant association similar to another study. ${ }^{20}$

\section{Conclusions}

DLP, a major risk for chronic heart disease, remains largely undiagnosed and untreated in high risk populations, such as patients with T1DM. DLP is a common health problem among Bangladeshi children and adolescents. So, the findings of our study provide useful information for health policy makers to implement action-oriented interventions for the prevention and early control of these important risk factors for CVD. We found a substantial proportion (64.9\%) of children and adolescents with T1DM had DLP. The 
most frequent type of DLP was high TG alone or in combination with other parameters in $54.3 \%$ of children and adolescents with T1DM and DLP in this population was associated with poor glycemic control. Majority of the participants $(63.4 \%)$ had poor glycemic control in this study. Significant difference of lipid parameters in two groups $(\mathrm{HbA} 1 \mathrm{c}<9 \%$ and $\geq 9 \%$ ) indicates that $\mathrm{HbA} 1 \mathrm{c}$ can be used as a potential biomarkers for predicting DLP in T1DM patients in addition to glycemic control hence early diagnosis can be accomplished through relatively inexpensive blood testing. These findings suggest that there is intense need for early interventions to prevent complications in future. DLP can serve as early biomarker for cardiovascular dysfunction in children and adolescents with T1DM. Early detection and treatment of these conditions prevent complications and further decrease the morbidity and mortality. Thus monitoring of the lipid levels in serum along with glycemic control has diagnostic and prognostic importance in T1DM. The important impact of DLP on complications requires undivided attention throughout the course of disease.

\section{References}

1. Azad K. Type 1 diabetes: the Bangladesh perspective. Indian J Endocrinol Metab 2015;19(Suppl 1):S9-11.

2. Mohsin F, Zabeen B, Zinnat R, Azad K, Nahar N. Clinical profile of diabetes mellitus in children and adolescents under eighteen years of age. Ibrahim Medical College Journal 2007;1(1):11-5.

3. Pinhas-Hamiel O, Dolan LM, Daniels SR, Standiford D, Khoury PR, Zeitler P. Increased incidence of non-insulindependent diabetes mellitus among adolescents. J Pediatr 1996;128:608-15.

4. Mona HM, Sahar SA, Hend SM, Nanees AWA. Dyslipidemia in type 1 diabetes mellitus: relation to diabetes duration, glycemic control, body habitus, dietary intake and other epidemiological risk factors. Egypt Pediatr Assoc Gaz 2015;63(2):63-8.

5. Salem MA, AboEIAsar MA, Elbarbary NS, ElHilaly RA, Refaat YM. Is exercise a therapeutic tool for improvement of cardiovascular risk factors in adolescents with type 1 diabetes mellitus? A randomized controlled trial. Diabetol Metab Syndr 2010;2(1):47.

6. Boitan M, Grigore M, Banciu AM. Dyslipidemia in diabetes mellitus patients- a major risk factor in cardiovascular disease. Acta Medica Transilvanica 2015;20(3):62-4.

7. Hassan MM, Sharaf SA, Soliman HM, Al-Wakeel NA. Dyslipidemia: a cardiovascular risk factor in type 1 diabetes and its correlations. J Diabetes Metab 2015;6(8):586.

8. Dabas A, Yadav S, Gupta VK. Lipid profile and correlation to cardiac risk factors and cardiovascular function in type 1 adolescent diabetics from a developing country. Int J Pediatr 2014;2014:513460.

9. Homma TK, Endo CM, Saruhashi T, et al. Dyslipidemia in young patients with type 1 diabetes mellitus. Arch Endocrinol Metab 2015;59(3):215-9.

10.Vergès BL. Dyslipidemia in diabetes mellitus. Review of the main lipoprotein abnormalities and their consequences on the development of atherogenesis. Diabetes Metab 1999;Suppl 3:32-40.

11. Kim SH, Jung IA, Jeon YJ, et al. Serum lipid profiles and glycemic control in adolescents and young adults with type 1 diabetes mellitus. Ann Pediatr Endocrinol Metab 2014;19:191-6.

12. Milicevic Z, Raz I, Beattie SD, et al. Natural history of cardiovascular disease in patients with diabetes: role of hyperglycemia. Diabetes Care 2008;31(Suppl 2):S155-60.

13. National Cholesterol Education Program (NCEP) Expert Panel on Detection, Evaluation, and Treatment of High Blood Cholesterol in Adults (Adult Treatment Panel III). Third Report of the National Cholesterol Education Program (NCEP) Expert Panel on Detection, Evaluation, and Treatment of High Blood Cholesterol in Adults (Adult Treatment Panel III) final report. Circulation 2002;106(25):3143-421.

14.American Diabetes Association. Management of dyslipidemia in children and adolescents with diabetes. Diabetes Care 2003;26:2194-7.

15.Azad K, Parkin JM, Court S, Laker MF, 
14.American Diabetes Association. Management of dyslipidemia in children and adolescents with diabetes. Diabetes Care 2003;26:2194-7.

15.Azad K, Parkin JM, Court S, Laker MF, Alberti KG. Circulating lipids and glycaemic control in insulin dependent diabetic children. Arch Dis Child 1994;71(2):108-13.

16.Libby P, Nathan DM, Abraham K, et al. Report of the National Heart, Lung, and Blood Institute-National Institute of Diabetes and Digestive and Kidney Diseases Working Group on Cardiovascular Complications of Type 1 Diabetes Mellitus. Circulation 2005;111(25):3489-93.

17.Patiakas S, Kiriakopoulos N, Gavala C, et al. The lipid profile of patients with diabetes mellitus in Paionia country. Diabetol Stoffwechs 2007;2:A35.

18.Rahma S, Rashid JA, Farage AH. The significance of lipid abnormalities in children with insulin dependent diabetes mellitus. Iraqi Postgrad Med J 2006;5:289-94.

19.Wiltshire EJ, Hirte C, Couper JJ. Dietary fats do not contribute to hyperlipidemia in children and adolescents with type 1 diabetes. Diabetes Care 2003; 26(5):1356-61.

20.Ahmed JO. Prevalence of dyslipidemia in children with type 1 diabetes in Kartoum state. MD thesis in Pediatrics and Child Health, University of Khartoum, 2005.

21. Alrabaty AA, Alnakshabandi AA, Yahya NB. The lipid profile in children with type 1 diabetes mellitus in Erbil governorate. Iraqi Postgrad Med J 2009;8:344-9.

22. Moayeri $\mathrm{H}$, Oloomi $\mathrm{Z}$. Prevalence of dyslipidemia in children and adolescents with diabetes mellitus type 1 . Iran J Pediatr 2006;16:171-6.

23.Kantoosh MM, Naiem AM, El-Sayad M, Nashat M. Dyslipidemia and lipid peroxidation in type 1 diabetic children with good glycemic control: response to antioxidant therapy. Alex $\mathrm{J}$ Pediatr 2002;16:357-64.
24. Herman $\mathrm{WH}$, Aubert RE, Engelgau MM, et al. Diabetes mellitus in Egypt: glycaemic control and microvascular and neuropathic complications. Diabet Med 1998;15(12):1045-51.

25.Al-Naama LM, Kadhim M, Al-Aboud MS. Lipid profile in children with insulin dependent diabetes mellitus. J Pak Med Assoc 2002;52:29-36.

26.Pollak A, Widhalm K, Havelec L, Frisch $H$, Schober E. Glycosylated hemoglobin $(\mathrm{HbA1c})$ and plasma lipoproteins in juvenile onset diabetes mellitus. Acta Paediatr Scand 1980;69:475-9.

27.Schwab KO, Doerfer J, Hecker W, et al. Spectrum and prevalence of atherogenic risk factors in 27358 children, adolescents and young adults with type 1 diabetes. Diabetes Care 2006;29:218-25.

28. Krantz JS, Mack WJ, Hodis HN, et al. Early onset of subclinical atherosclerosis in young persons with type 1 diabetes. $J$ Pediatr 2004;145:452-7.

29.Wadwa RP, Kinney GL, Maahs DM, et al. Awareness and treatment of dyslipidemia in young adult with type 1 diabetes. Diabetes Care 2005;28(5):1051-6.

30.Maahs DM, Wadwa RP, McFann K, et al. Longitudinal lipid screening and use of lipid-lowering medications in pediatric type 1 diabetes. J Pediatr 2007; 150(2):146-50.

31.Guy J, Ogden L, Wadwa RP, et al. Lipid and lipoprotein profiles in youth with and without type 1 diabetes: the SEARCH for diabetes in youth case-control study. Diabetes Care 2009;32:416-20.

32.Teles SA, Fornés NS. Relationship between anthropometric and biochemical profiles in children and adolescents with type 1 diabetes. Rev Paul Pediatr 2012;30:65-71.

33. Muchacka-Bianga M, Deja G, JaroszChobot P, Małecka-Tendera E, Kalina M, Grychtoł M. Evaluation of selected risk factors of atherosclerosis in children with type 1 diabetes mellitus and hypercholesterolemia. Endokrynol Diabetol Chor Przemiany Materii Wieku Rozw 2006;12:25-30.

\section{Suggestion for citation of the above:}

Parveen M, Muttalib MA, Huq ST, Nazneen N, Kabir MA, Hossain MS. Evaluation of lipid profile among children and adolescents with type 1 diabetes mellitus in Bangladesh. Mediscope 2018;5(1):15-21. 